\title{
Comparison of Various Levels of Parallel Multilevel Active Filter Using NPC Multilevel Inverter
}

\author{
Farouk Hadj Benali, Fouad Azzouz \\ Electrotechnic Department, Electrical Engineering Faculty, USTO-MB University, Algeria
}

\begin{tabular}{|c|c|}
\hline Article Info & ABSTRACT \\
\hline Article history: & \multirow{6}{*}{$\begin{array}{l}\text { This paper puts forward the technique of reference signal generation of the } \\
\text { reactive instantaneous power and the technique of the SPWM control signal } \\
\text { generation of the multilevel active filter. A comparison between the source } \\
\text { currents before and after filtering is made. Then a comparison between the } \\
\text { different source currents of different multilevel active filters. The subjects of } \\
\text { comparison are the total harmonic distortions (THD) of the source current. } \\
\text { The obtained simulation results have proved that the filtering quality is } \\
\text { improved when increasing the active filter levels. Simulations are carried out } \\
\text { by PSIM program. }\end{array}$} \\
\hline Received Dec 10, 2015 & \\
\hline Revised Feb 10, 2016 & \\
\hline Accepted Feb 26, 2016 & \\
\hline Keyword: & \\
\hline Multilevel inverter & \\
\hline
\end{tabular}

NPC converter

Parallel multilevel active filter

SPWM

THD

Copyright $(2016$ Institute of Advanced Engineering and Science. All rights reserved.

Corresponding Author:

Farouk Hadj Benali,

Electrotechnic Department,

Electrical Engineering Faculty,

USTO-MB University,

El Mnaouar BP 1505, Bir El Djir 31000 Oran Algeria.

E-mail: farouk0409@hotmail.com

\section{INTRODUCTION}

The increasing use in industry of energy conversion static devices known as static converters leads to increasingly disturbance problems in electrical networks. Thus, increases in harmonic rates and current imbalance are expected, besides a consequent consumption of reactive power.

There are several remedial options to clean the electrical systems. That which best meets today industrial constraints is the active filtering (compensator active filter) [1].

The active filtering can be used to compensate the harmonic and unbalanced currents, the harmonic and unbalanced voltages, the voltage dips and even the reactive power [1], [2].

There are a number of active filter topologies [2], [3], [4]:

a. Series active filters,

b. Parallel active filters,

c. Hybrid active filters. Combination of an active and a passive filters,

d. Active filter based on multilevel inverters.

There are several control strategies for the active filter. The most widespread are:

a. The control strategies in the frequency domain. Based on the Fourrier analysis of the non sinusoidal voltage and current,

b. The control strategies in the time domain. The most known of these strategies is the instantaneous power method.

However the active filter does not meet the growing needs of the industry, this has led to seek out adequate solutions. One way is to increase the voltage level. But the rise of the semiconductor withstand voltage leads to a deterioration of their static and dynamic performances. This constraint has led to the 
substitution of the active filter conventional inverter by a multilevel inverter. This combination gives rise to the multilevel active filters. The output of multilevel inverter is a staircase wave, which is nearly sinusoidal $[5]$.

For three phase applications and for a small number of levels, the NPC inverters are interesting, since the capacitors are shared between the different branches, resulting in the balancing of the power flowing through the phases. Thus the most suitable converter for our application is the NPC multilevel inverter.

The paper starts with a presentation of the active filter followed by a recall of the Neutral Point Clamped multilevel inverter NPC. Definitions of the technique of reference signal generation for the reactive instantaneous power and the technique of the SPWM control signal generation are given on the ensuing section. Finally a discussion of the simulated results is presented.

\section{STRUCTURE OF THE PARALLEL MULTILEVEL ACTIVE FILTER OR SHUNT (APFs)}

The multilevel active filter is constituted of two parts. The power circuit is structured into a multilevel inverter, a coupling filter and a passive element which serves as an energy source. The control circuit serves to monitor the switching of the semiconductor elements that form the inverter of the power circuit.

By means of appropriate control strategies, we can generate harmonic signals at the inverter output in order to compensate those present in the electrical nework [6].

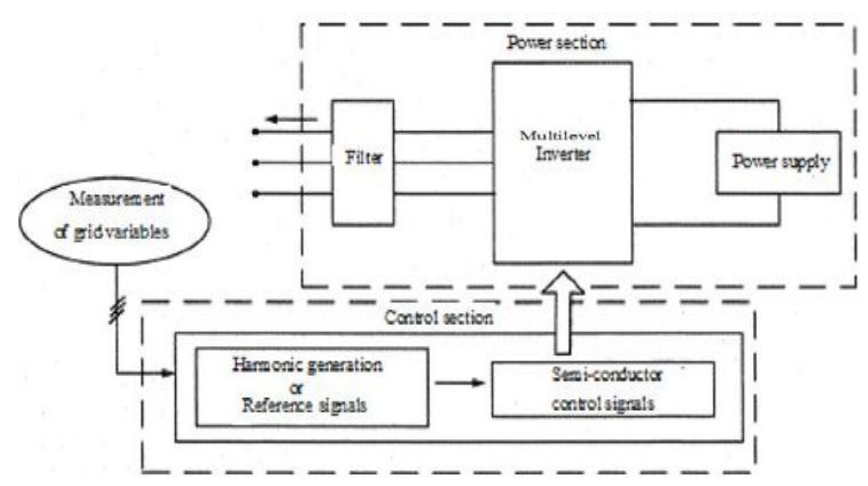

Figure 1. General structure of a parallel active filter

\section{NEUTRAL POINT CLAMPED MULTILEVEL INVERTER (NPC)}

The NPC inverter is proposed by Baker [7]. This inverter allows obtaining a voltage odd level [8], [9]. The first NPC inverter has been developped for a three level output voltage through superposition of two basic switches each supplied by a separate DC voltage source.

This multilevel structure is called neutral clamped. This kind of technique allows installing the switches in series for high voltage applications. The distribution of the E voltage over the different power switches in series is this time ensured by diodes connected with the center tap.

The voltage across the capacitors is equal to:

$\mathrm{Vck}=\mathrm{E} /(\mathrm{N}-1)$;

$\mathrm{k}=1,2$

This type of inverter is shown in Figure 2.

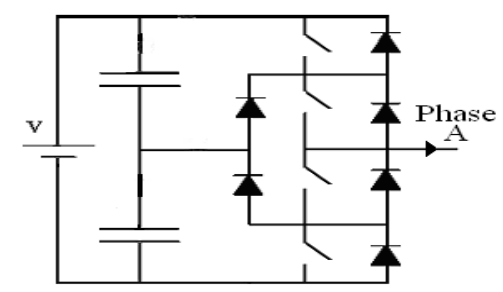

Figure 2. NPC three level inverter (per phase) 


\section{ACTIVE FILTER CONTROL}

As shown in Figure 1, the control part is generally divided into two sections. The first one, which is of significant importance for the filter performances, is to generate reference harmonic signals. The second one, is the generation of control signals to open and close the semi conductors. Both parts are crucial in the active filter performance.

\subsection{Generation of Reference Signals by the Power Reactive Instantaneous Method}

This method is based on the measure of three phase instantaneous variables contained in the electrical network with or without negative sequence components [10], [11]. This method is equally valid in steady and transient states.

In the control algorithm, the voltage and current measurements expressed in three phase form (abc) are converted in an equivalent two phase system $(\alpha \beta)$ using the Concordia Transformation [12] which leaves the power invariant.

$$
\left[\begin{array}{l}
v_{\alpha} \\
v_{\beta}
\end{array}\right]=\sqrt{3 / 2}\left[\begin{array}{ccc}
1 & -1 / 2 & -1 / 2 \\
0 & \sqrt{3} / 2 & -\sqrt{3} / 2
\end{array}\right]\left[\begin{array}{l}
v_{a} \\
v_{b} \\
v_{c}
\end{array}\right]
$$

That gives us:

$$
\begin{aligned}
& p=v_{\alpha} \cdot i_{\alpha}+v_{\beta} \cdot i_{\beta} \\
& p=v_{\alpha} \cdot i_{\beta}-v_{\beta} \cdot i_{\alpha}
\end{aligned}
$$

The instant actual power and the instant fictitious power can be expressed in the following way:

$$
\begin{aligned}
& p=\bar{p}+\tilde{p} \\
& q=\bar{q}+\tilde{q}
\end{aligned}
$$

Where $\bar{p}$ and $\bar{q}$ are respectively, the components of active and reactive average powers corresponding to the fondamental load current $(50 \mathrm{~Hz})$, while $\tilde{p}$ and $\tilde{q}$ correspond to the alternative components linked to the harmonic current. The harmonic compensation by the active filter is done through the generation of the latter.

$$
\tilde{p}=\mathrm{p}^{*} \quad, \quad \tilde{q}=\mathrm{q}^{*}
$$

Consequently, the removal of the fondamental component in equations (8) is carried out using two low pass filters of second order.
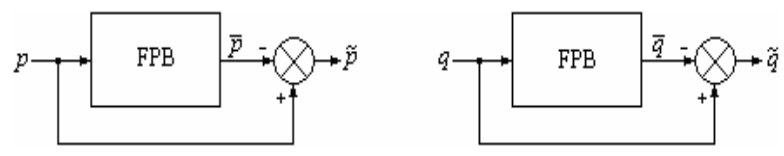

Figure 3. Low pass filter used

The reference compensation currents shall be calculated by the following formula

$$
\left[\begin{array}{l}
i_{a}^{*} \\
i_{b} * \\
i_{c} *
\end{array}\right]=\sqrt{3 / 2}\left[\begin{array}{cc}
1 & 0 \\
-1 / 2 & \sqrt{3} / 2 \\
-1 / 2 & -\sqrt{3} / 2
\end{array}\right]\left[\begin{array}{c}
i_{\alpha} * \\
i_{\beta} *
\end{array}\right]
$$

Where,

$$
\left[\begin{array}{l}
i_{\alpha}^{*} \\
i_{\beta} *
\end{array}\right]=\left[\begin{array}{cc}
v_{\alpha} & v_{\beta} \\
-v_{\beta} & v_{\alpha}
\end{array}\right]\left[\begin{array}{l}
p^{*} \\
q^{*}
\end{array}\right]
$$




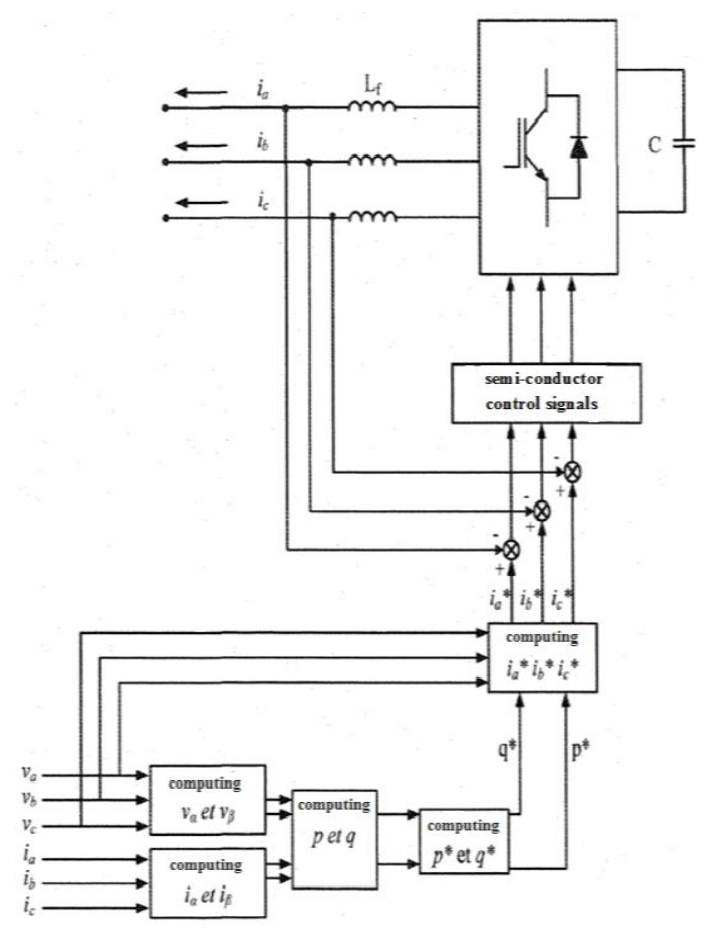

Figure 4. Active filter controlled by the instantaneous power method

\subsection{Control Signal Generation by the Pulse Width Modulation (SPWM) Technique}

Another important step is to generate control signals for the semiconductors of active filter inverter. These control signals are obtained from the harmonic compensation signals seen in the previous section. In this method, the difference between the reference current $i_{a}$ and the filter current $i_{a}{ }^{*}$ is applied to the input of a Proportional-Integral controller PI. The regulator output signal will then be compared to one or more triangle carriers Up which have the same amplitude $A_{p}=2 /(N-1)$ and the same frequency $f p$ [13].

Each comparison gives 0 if the modulating signal is higher than the carrier. Otherwise it gives 1 . The sum of signals obtained from the comparisons gives the phase voltage value of each level.

Two parameters typify this strategy [14]:

Modulation index: $Q=f_{p} / f$

Voltage adjustment coefficient: $r=A_{m} /\left((N-1) A_{p}\right.$

The Figure 5 shows the necessary signals to generate a five level voltage, with $Q=30$ and $r=1$.

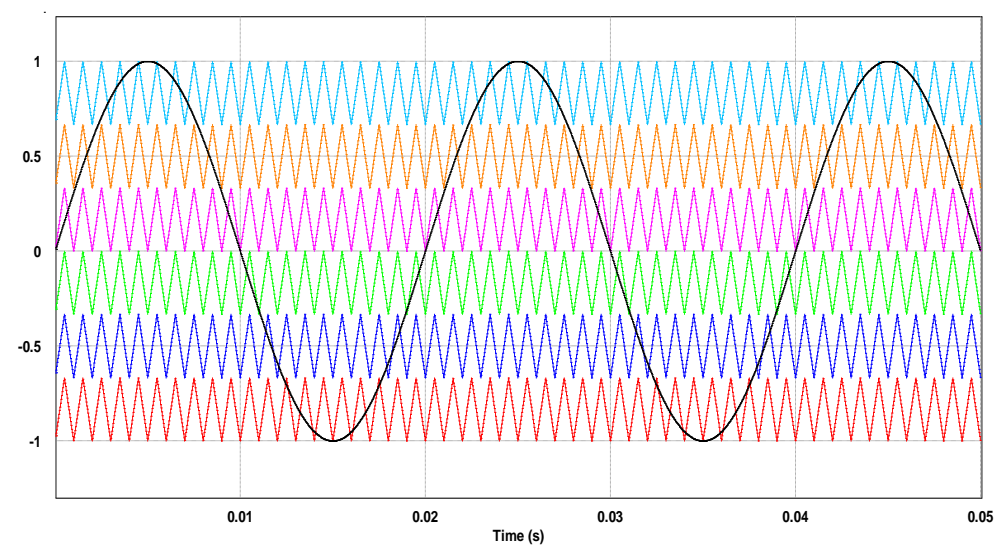

Figure 5. Reference voltage and triangle carriers for a five multilevel inverter $(Q=20, r=1)$ The diagram of natural sampling SPWM control is illustrated on Figure 6. 


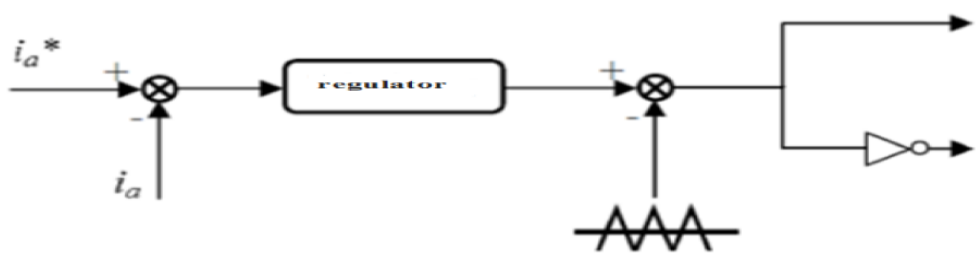

Figure 6. Principle of control currents by SPWM

\section{SIMULATION RESULTS}

To test the feasibility of the multilevel active filter, we use a comparative study based on the THD of output courant Isa (A) for the 2, 3, 5 and 7 NPC multilevel inverter.

The 2, 3, 5 and 7 multilevel active filter simulations are carried out by PSIM program. In order to get the THD level of the waveform, a Fast Fourrier Transform (FFT) of PSIM program is applied to obtain the spectrum of the output courant.

For the comparison, the THD and the fundamental voltage are measured and presented for all simulations.

Figure 7 represents 2, 3, 5 and 7 multilevel active filters.

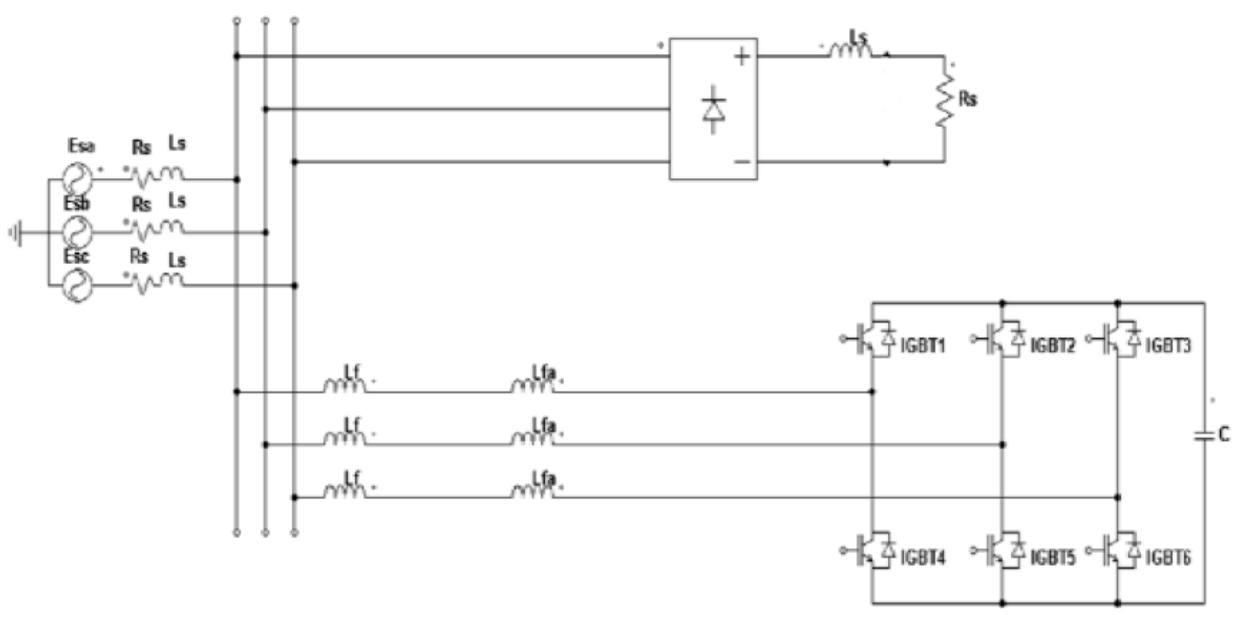

(a)

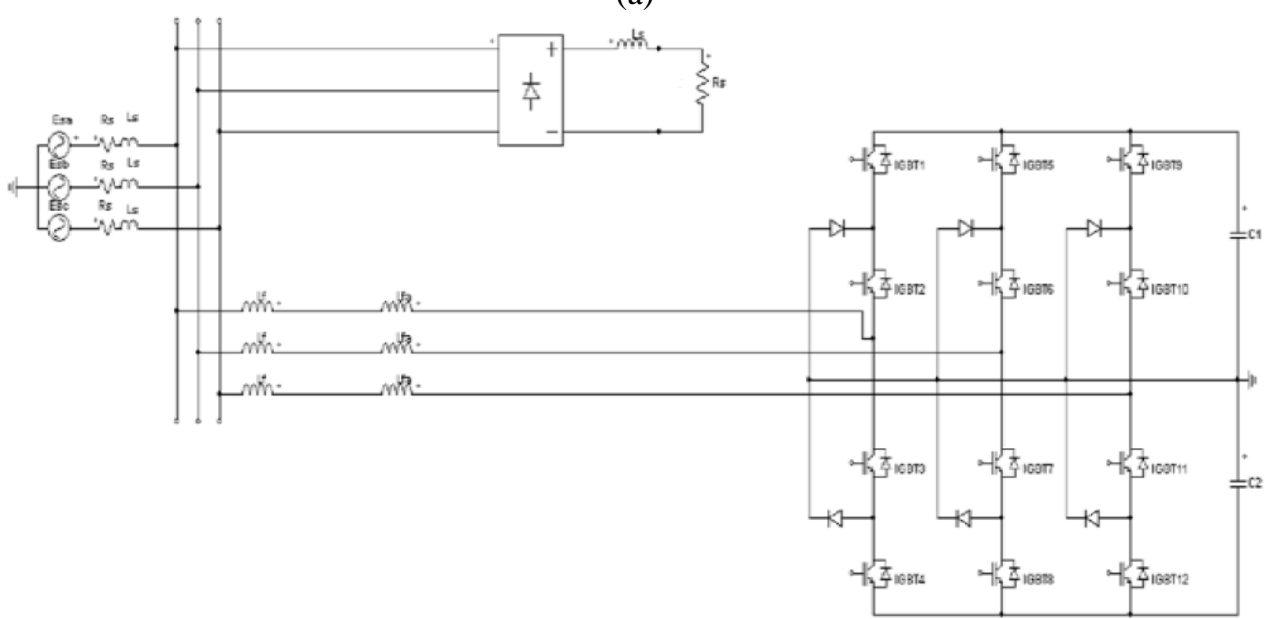

(b) 


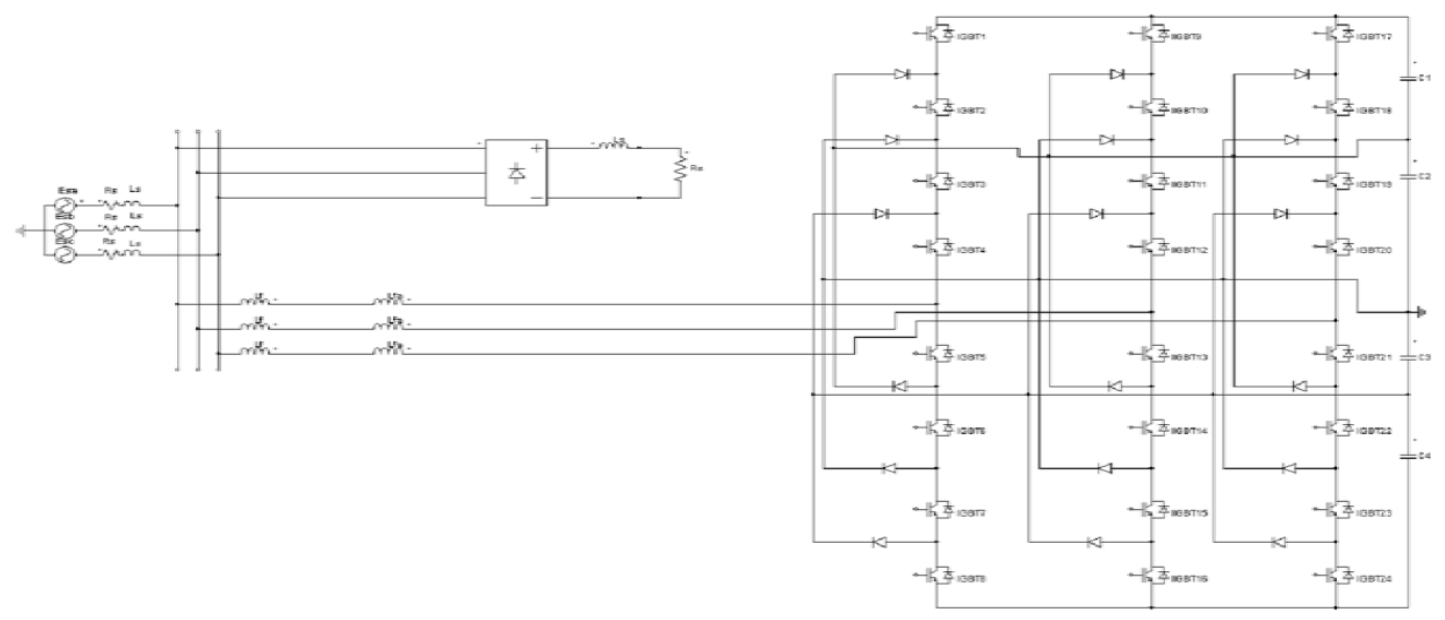

(c)

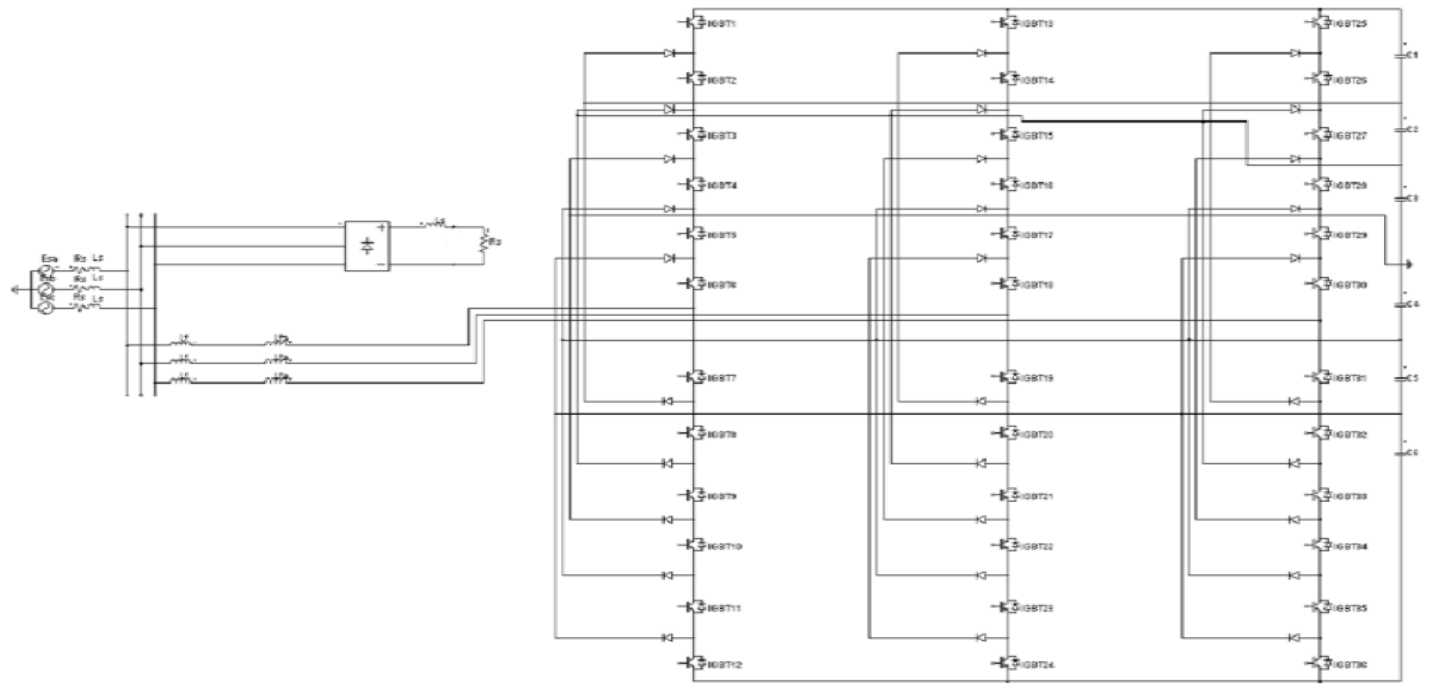

(d)

Figure 7. (a) 2-level active filter, (b) 3-level active filter, (c) 5-level active filter, (d) 7-level active filter

\subsection{Before Use of the Active Filter}

Figure 8 and Figure 9 show the current waveform Isa $(A)$ and its harmonic spectrum for the electrical network before compensation.

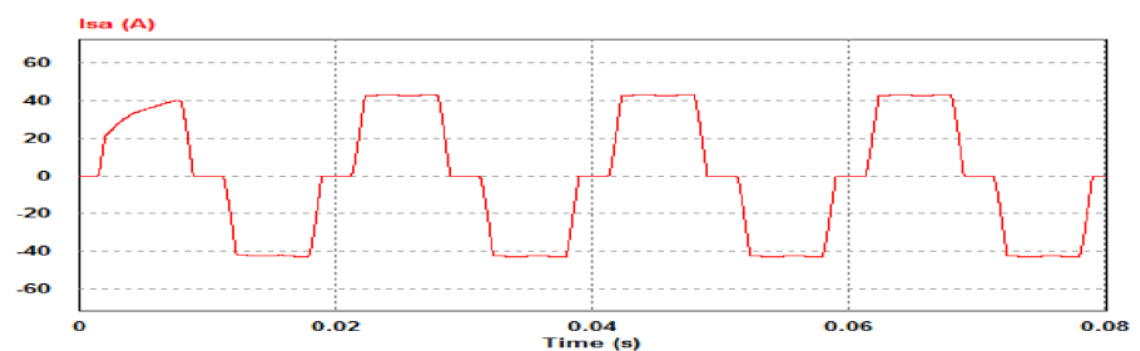

Figure 8. The source current Isa (A) before compensation 


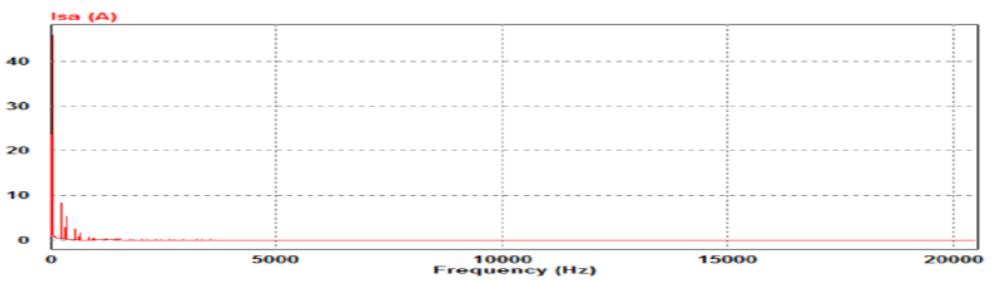

Figure 9. Current harmonic spectrum of the source before compensation

\subsection{Two-Level Active Filter Simulations}

Figure 10, Figure 11, Figure.12 and Figure.13 show the current waveform Ifa (A), the current waveform Isa $(A)$, its harmonic spectrum and a closer look for the 2-level active filter.

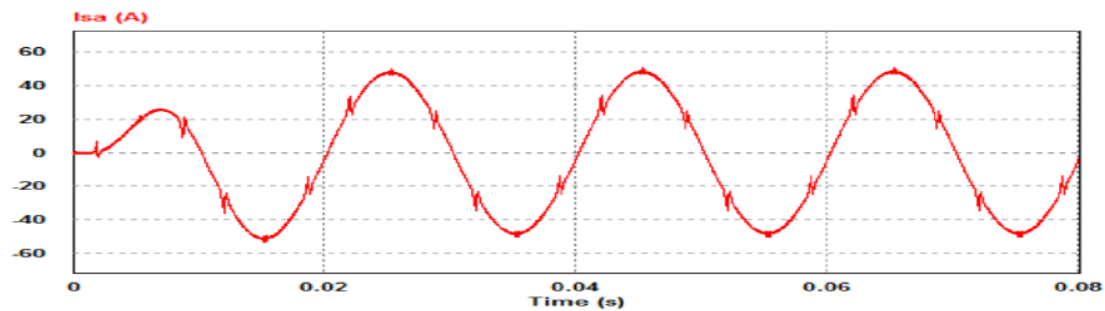

Figure 10. Source current Isa (A)

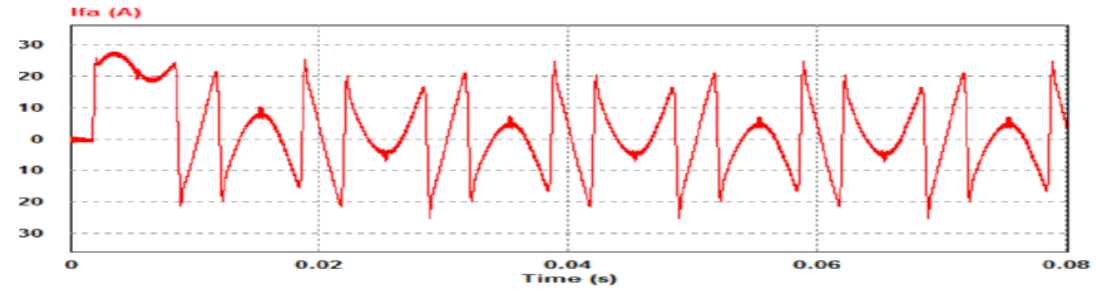

Figure 11. Filter current Ifa (A)

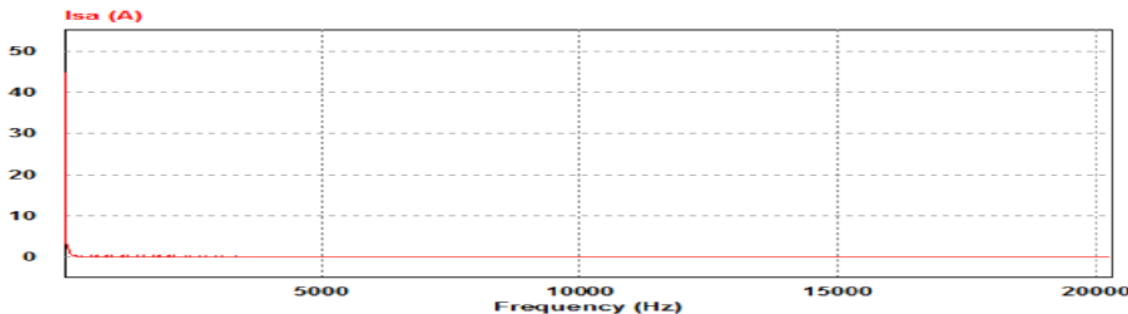

Figure 12. Harmonic spectrum of the source current Isa (A) after compensation

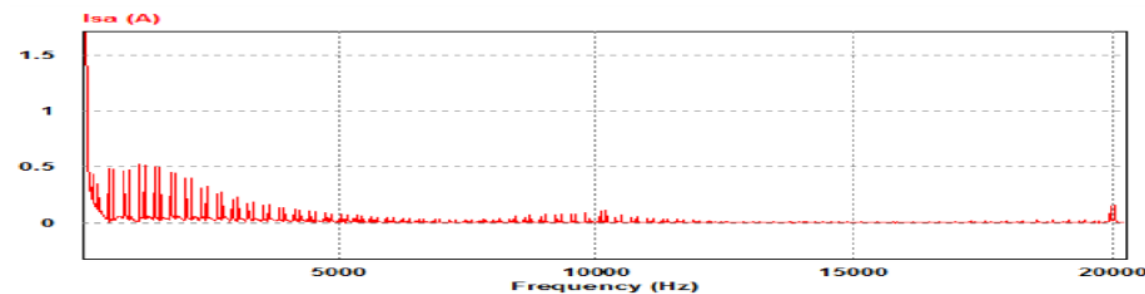

Figure 13. Closer look for Harmonic spectrum of the source current Isa (A) 
According to the Figure 9 and Figure 12 Which show respectively the harmonic spectrum of the source current before and after compensation, we found the total harmonic distorsion THD before compensation current injection was $22.82 \%$ and $4.41 \%$ after compensation current injection. The result is a significant improvement in terms of quality of the source current.

\subsection{Three-Level Active Filter Simulations}

Figure.14, Figure.15, Figure.16 and Figure.17 show the current waveform Ifa (A), the current waveform Isa $(A)$, its harmonic spectrum and a closer look for the 3-level active filter.

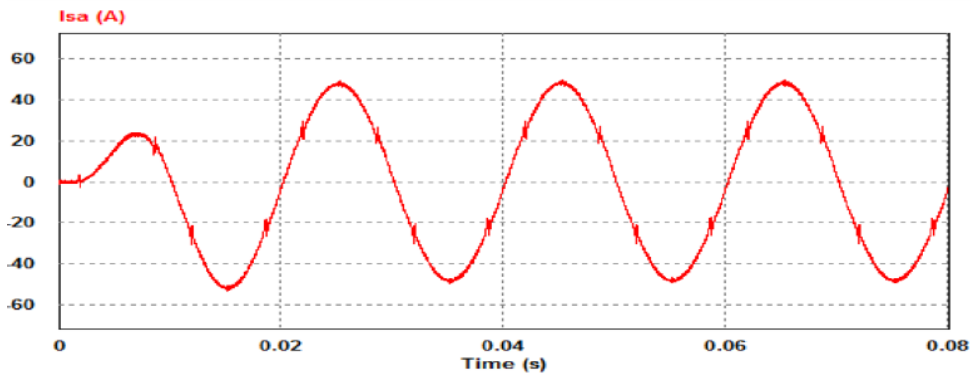

Figure 14. Source current Isa (A)

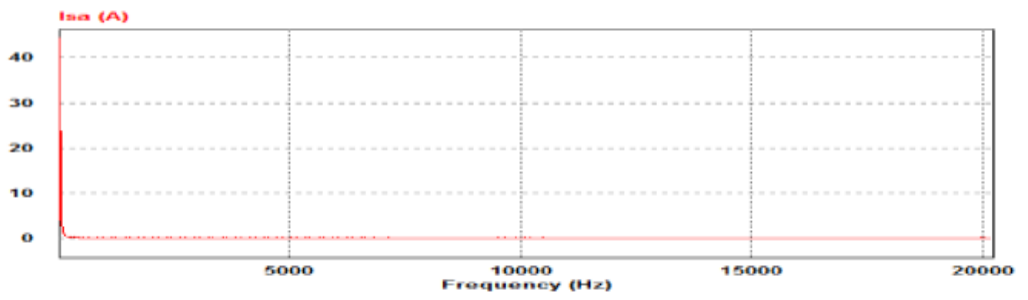

Figure 16. Harmonic spectrum of the source current Isa (A) after compensation

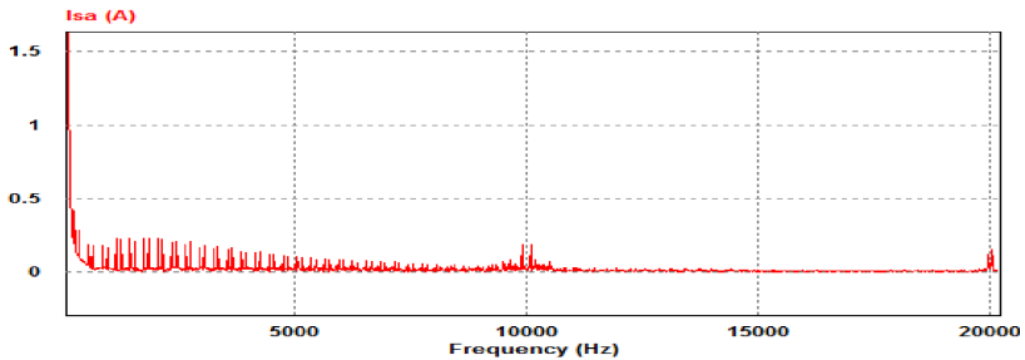

Figure 17. Closer look for Harmonic spectrum of the source current Isa (A)

According to the Figure 12 and Figure 16 which show respectively the harmonic spectra of the two and three level filter source current, we note that the total harmonic distorsion THD of the three level filter $(2.84 \%)$ is lower than the two level filter THD $(4.41 \%)$, which will improve further the quality of the source current.

\subsection{Five-Level Active Filter Simulations}

Figure 18, Figure 19, Figure 20 and Figure 21 show the current waveform Ifa (A), the current waveform Isa $(A)$, its harmonic spectrum and a closer look for the 5-level active filter. 


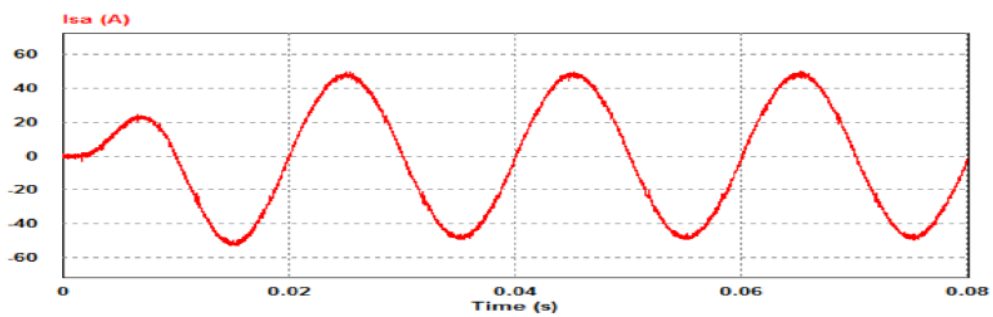

Figure 18. Source current Isa (A)

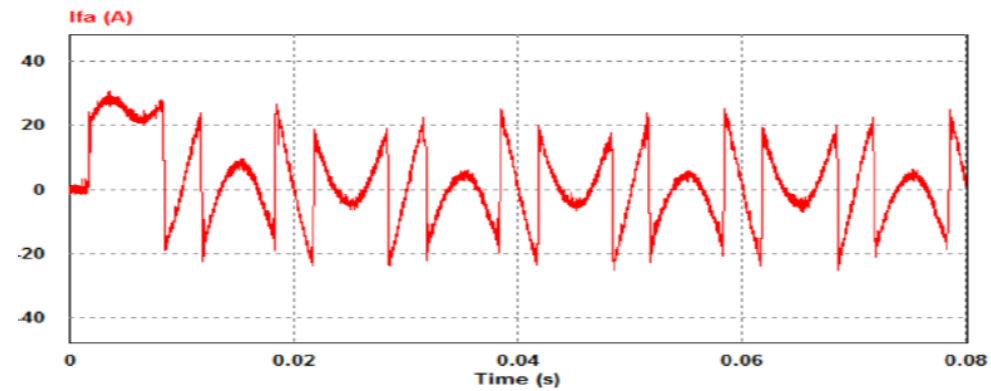

Figure 19. Filter current Ifa (A)

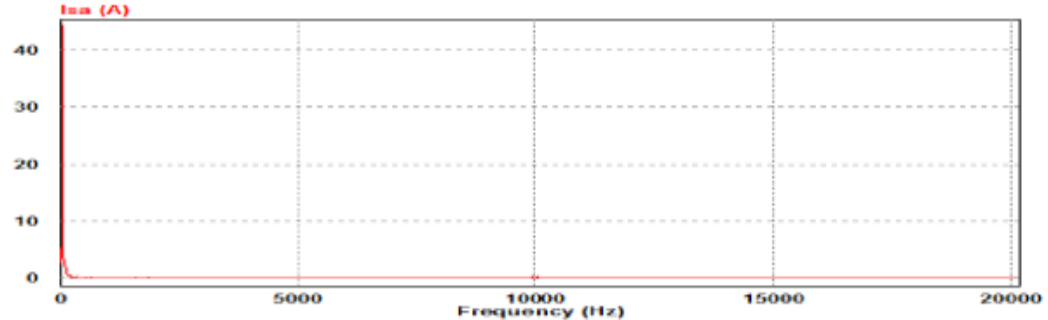

Figure 20. Harmonic spectrum of the source current Isa (A) after compensation

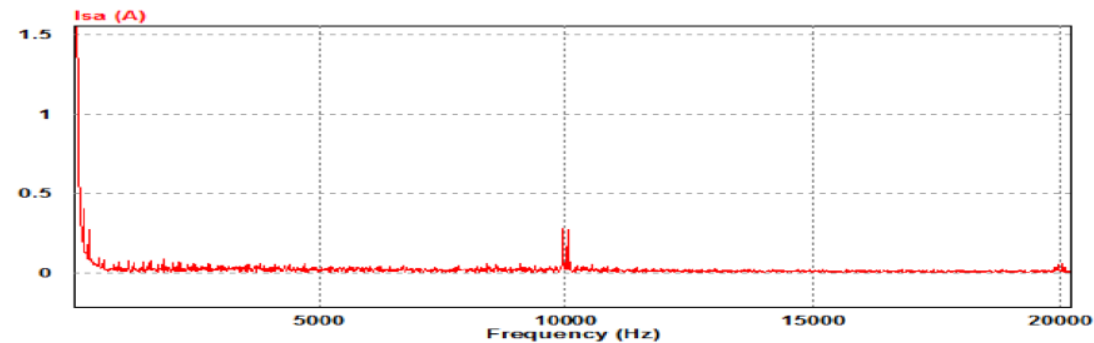

Figure 21. Closer look for Harmonic spectrum of the source current Isa (A)

According to the Figure 16 and Figure 20 which show respectively the harmonic spectra of the three and five level filter source current. We note that the total harmonic distorsion THD of the five level filter $(2.36 \%)$ is lower than the three level filter THD $(2.84 \%)$, which will improve further the quality o the source current.

\subsection{Seven-Level Active Filter Simulations}

Figure.22, Figure.23, Figure.24 and Figure.25 show the current waveform Ifa (A), the current waveform Isa $(A)$, its harmonic spectrum and a closer look for the 7-level active filter. 


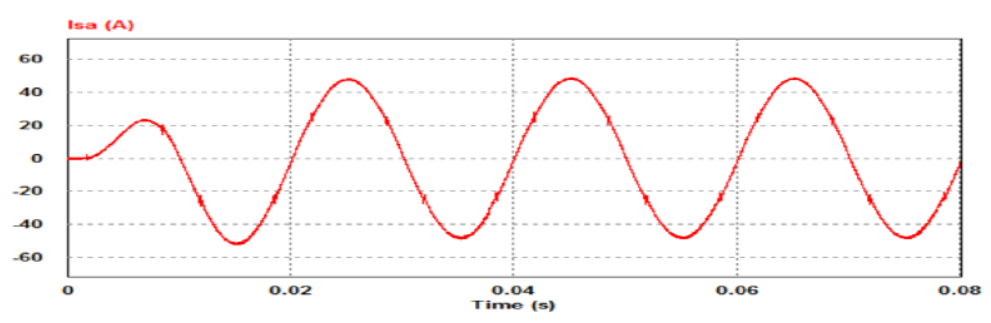

Figure 22. Source current Isa (A)

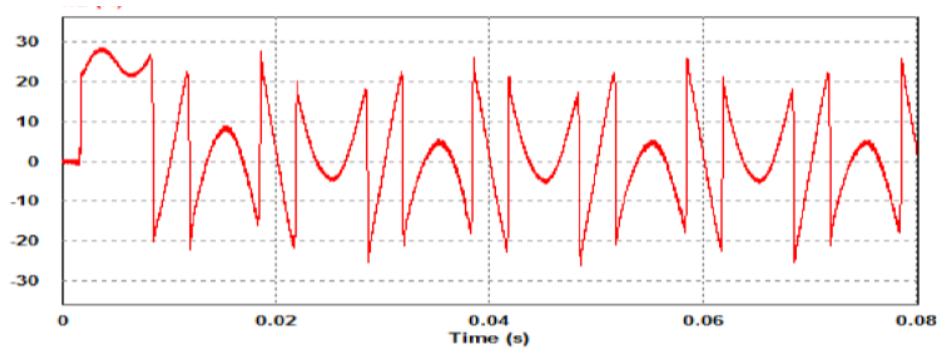

Figure 23. Filter current Ifa (A)

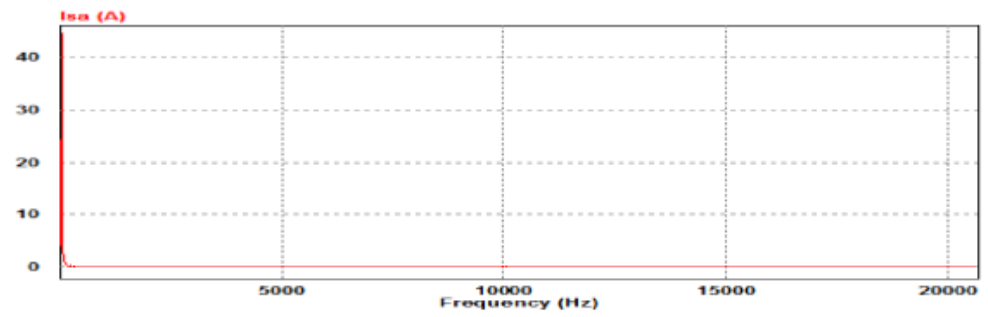

Figure 24. Harmonic spectrum of the source current Isa (A) after compensation

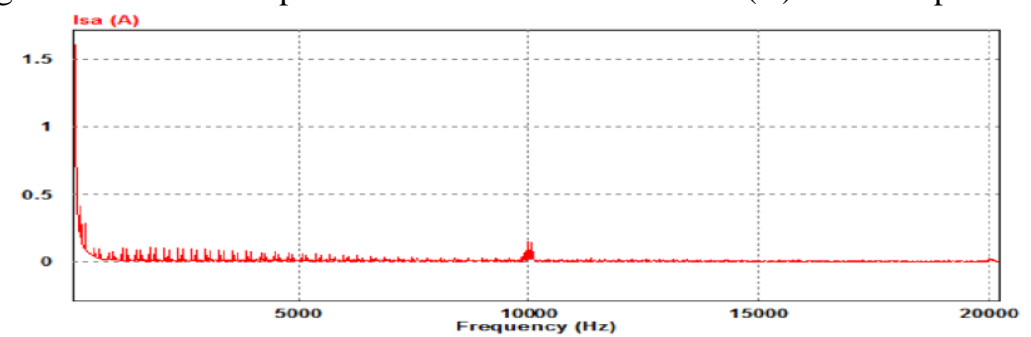

Figure 25. Closer look for Harmonic spectrum of the source current Isa (A)

According to the Figure 20 and Figure 24 which show respectively the harmonic spectra of the three and five level filter source current. We note that the total harmonic distorsion THD of the five level filter $(1.73 \%)$ is lower than the three level filter THD $(2.36 \%)$, which will improve further the quality o the source current.

\section{ANALYSIS OF RESULTS}

The table below aggregates all the obtained simulation results; 
Table 1. Simulation Results

\begin{tabular}{cc}
\hline Source current & THD (\%) \\
\hline Without active filter & 22.82 \\
2-level active filter & 4.41 \\
3-level active filter & 2.84 \\
5-level active filter & 2.36 \\
7-level active filter & 1.73 \\
\hline
\end{tabular}

According to the table above, we find that the THD of 7 level filter is lower than that of five levels. The THD of 5 level filter is lower than that of 3 levels. And the THD of the 3 level filter is lower tan that of two levels.

Thus we can deduce that the filtering quality is getting better in moving from a lower level filter to a higher level filter.

\section{CONCLUSION}

In this paper, the generation method of reference signals of reactive instant power and the generation method of SPWM control signals of multilevel active filter are presented.The total harmonic distorsions THD are measured, grouped and analysed.

It is found that the filtering quality is improved when increasing the active filter levels. Despite the fact that the difference of THD between different active filter levels is less than $3 \%(0.48 \%$ to $2.68 \%)$, there is no denying the superiority of the seven active filter compared to the two, three and five level active filters.

\section{REFERENCES}

[1] Alireza Javadi., " Modeling, simulation and real time control of active filter," These en vue de l'obtention du Diplome de Maitrise es sciences appliquées de l'Université de Montréal, 2009.

[2] F.Z. Peng, D.J. Adams., "Harmonie sources and filtering approachesseries/ parallel, active/passive, and their combined power filters", in Record Conference, 1999. Thirty-Fourth IAS IEEE Annual Meeting, 1999 pp. 128-131.

[3] F.Z. Peng., «Application issues of active power filter," IEEE Industry Applications Magazine, 1998, pp. 21-30.

[4] S. Mouttou., " Nouvelles approches de commande d'un filtre actif parallèle à source de courant," These en vue de l'obtention du Diplome de Maitrise Université du Québec à Trois-Rivières, 2002.

[5] Gnana Prakash M, Balamurugan M, Umashankar S., "A New Multilevel Inverter with Reduced Number of Switches," International Journal of Power Electronics and Drive System (IJPEDS), July 2014, pp. 63-70.

[6] Steeve Beaulieu, " Etude et mise au point d'un filtre actif d'harmoniques en vue d'améliorer la qualité de l'alimentation électrique," These en vue de l'obtention du Diplome de la Maîtrise en Ingénierie Université du Québec, 2007.

[7] A. Nabae, I. Takahashi, H. Akagi., " A new neutral-point clamped PWM inverters," IEEE Trans. Ind. Applicat,1981, pp. 518-523.

[8] N. Celanovic., «Space Vector Modulation and Control of Multilevel Converters," Ph.D Thesis, Virginia Polytechnic Institute, 2000.

[9] N. Celanovic, D. Boroyevich., " A Comprehensive Study of Neutral-Point Voltage Balancing Problem in Three Level Neutral-Point-Clamped Voltage Source PWM Inverters," in record conference IEEE-APEC, 1999.

[10] H. Akagi, Y. Kanazawa, \& A. Nabae., "Instantaneous reactive power compensators comprising switching devices without energy storage components," IEEE Trans. Ind. Applicat, 1984, pp. 625-630.

[11] H. Akagi, Y. Tsukamoto, and A. Nabae., "Analysis and design of an active power filter using quad-series voltage source PWM converters," IEEE Trans. Ind. Applicat, 1990, Vol.26.

[12] J. Lesenne, F. Notelet, \& G. Seguier., "Introduction à l'électrotechnique approfondie," Ed. Technique \& Documentation, 1981, pp. 53-73.

[13] Farouk Hadj Benali, Ghalem Bachir, Fouad Azzouz., " The Operating Improvement of the Supply Source and the Optimization of PWM Control," International Journal of Power Electronics and Drive System (IJPEDS), July 2015, pp. 03-14.

[14] Daniel Depernet., "Optimisation de la commande d'un onduleur MLI à trois niveaux de tension pour machine asynchrone," Thèse pour l'obtention du grade de Docteur de l'Université de Reims Champagne-Ardenne, 1995. 